\title{
Too much information: when the burden of trust paralyses representation
}

\section{Kristina Everett}

This story is not a simple one, nor, very likely, an unfamiliar one to anyone who has conducted research in Indigenous contexts. It began when a long time Aboriginal friend, 'Alma', ' asked me to help her to write her story so that her children, grandchildren, future descendants and the general public could know about her life. Due to the educational conditions Alma experienced in her childhood, she believed that her literacy skills were not up to the task of doing justice to her complex and compelling story, so she asked me, a white friend with a tertiary education and a sympathetic ear, to undertake the job. We agreed that this was to be a collaborative work based largely on an account and analysis of our relationship and the ways in which our stories as 'inter-racial' friends are intertwined, vexed, segregated and silenced. A difficult enough task I thought, until I realised after years of writing and further research, that it may well be an impossible one. I have come to understand that what began as a project to help write my friend back into Australian history could have dire ramifications for many different people, including myself. Some of the information in the biography could undermine the claims of Alma's community and of some other Aboriginal people. It could not only damage future claims for reparation of past injustices by the Australian state, but could impair some people's claims to 'authentic' Aboriginal identity according to the rules of native title in this country. It could make it impossible for me to ever work in this area again. But having accepted the job of telling someone else's story, do I now have the right to refuse to seek its publication which is much desired by Alma and her community? Is this my choice?

\section{Introduction}

Much has been said about the rightness and especially the wrongness of relatively powerful, educated whites writing the stories of black people. Many authors including Stuart Hall, Henry Louis Gates, Mudrooroo, bell hooks and Aileen Moreton-Robinson, to name a few, question the possibility of any kind of non-colonial representation being possible in the process of cultural translation that must necessarily occur when a white author presumes to write someone else's story. ${ }^{2}$ Mari Rhydwen while acknowledging the kinds of problems raised by these authors, was among the first to also acknowledge that, in the era of native title and land claims, many Indigenous people not only accept the interest 
of white authors in compiling their biographies, autobiographies and life histories, but actively seek such attention. ${ }^{3}$ For many Indigenous people, biographies written by white authors have become an essential part, not only of their claims against the state, but of writing themselves, their families and their communities back into an Australian history out of which they were previously written. Gaynor Macdonald reminds us, however, that data obtained from informants with a vested interest in having their story told can only be a reflection of a moment in time, cannot tell 'the whole story', require that Indigenous participants represent themselves within particular 'frames' (authentic, traditional people) and more-over, co-opt researchers in the service of a specific cause for a particular group of people. ${ }^{4}$ In this paper I am concerned with these problems, especially the last two: that Indigenous participants in biographies and research generally must represent themselves as authentic, traditional people and that researchers are co-opted to reproduce these representations.

I was not naïve to the broader political ramifications of writing biography when Alma asked me to help her to write her life history. In 2001 I began collecting material - interviews, stories, copies of paintings, photos, maps and other documents. Alma and I had been close friends for many years, I knew her family, friends and was conscious of the wider community to which she belonged and was aware of some of their political concerns. Alma is a senior woman who belongs to a group called 'Galba' who claim traditional Aboriginal ownership of a large part of a modern Australian metropolis. I thought at the time that helping Alma to write her biography may support some of the claims of the broader community, contribute to the literature on urban Aboriginal identity, and, equally importantly, be an affirming and empowering document recognising Alma's personal history as an Aboriginal woman within the Australian state over the last 60 years or so. I had just begun my $\mathrm{PhD}$ candidature in anthropology at the time and I asked Alma and other community leaders for permission to use the material I gathered for the biography to be also used in my anthropological research.

Galba can prove that they conform to the official definition of 'Aboriginal' in Australia. This definition is formulated in most state's Native Title Acts, and is the same as that used in the Commonwealth Native Title Act 1993 and in Section 51(26) of the Australian Constitution. In all this legislation 'Aboriginal' is defined as: 'a person of Aboriginal or Torres Strait Islander descent who identifies as an Aboriginal or Torres Strait Islander and is accepted as such by the community in which he or she lives'. So, in Australia, self and community cultural identification, as well as genetic descent, determine who is Aboriginal. The Australian legal definition is a social category conflated with genetic heritage. 
But identification as Aboriginal is not the same as being recognised as Aboriginal Traditional Owners. Under the Land Rights Act (NSW 1986), for example, Aboriginal people who have been alienated from their traditional, pre-contact countries may gain access and benefits to land with which they now have various kinds of connections. Under the Act these 'connections' do not need to pre-exist white settlement and may be related to histories of pastoral or industrial relationships with a particular tract of land or to long term settlement in a particular area. If, however, a group claims Aboriginal Traditional Ownership, the land is claimed under either the Commonwealth Native Title Act 1993 or one of the state's Native Title Acts. Under these Acts claimants must prove that they remain connected to a 'body of traditions, observances, customs and beliefs of Aboriginals or of a community or group of Aboriginals whose traditions, observances, customs and beliefs are applied to particular persons, sites, areas of land, things or relationships' ${ }^{5}$ In other words, claimants must prove that they remain, and have continuously been 'connected' to customs and beliefs that were existent before white people came to Australia. Proving ongoing connections to pre-contact Aboriginal traditions in the face of colonisation seems a most difficult task for any Indigenous group, but for people like Galba, whose traditional country is now an urban centre, this is virtually impossible.

What I was completely naïve about when I began researching the biography was the precise nature of the community to which Alma belonged: its unusual composition, its uncommon social structure and its difference from another group of people, also called Galba, who make similar claims in very different and competing ways. I knew that 'Alma's mob' may have once become a community in response to what they perceived to be the benefits of native title. But I did not completely grasp the serious repercussions of their more recent claim that their contemporary cultural expressions, such as singing, dancing and ceremony, are now such values in themselves that making land claims is now a secondary concern to them.

Alma's mob often perform public expressions of their group identity including 'welcome to country' speeches using a version of a pre-contact Aboriginal language, site smokings in which gum leaves are added to a fire to cleanse a particular space and the people inhabiting it of evil spirits, and Aboriginal dancing by performers wearing lap-laps with their bodies painted in white ochre. These performances are most often performed at the invitation of white officials at occasions such as opening ceremonies for exhibitions, local, state and federal government occasions, school functions and conferences. Alma's mob also engage in certain 'private' expressions of group identity including ceremonies that are not always meant to be observed by 'outsiders'. One of these is a ceremony performed after the death of a community member and involves the ritualised carving of a symbol of group identity into sacred trees. 
The various representations of 'Aboriginality' and articulations of group identity employed by Alma's mob are drawn from many different sources. They are part of ongoing political-cultural processes of conservation and restoration, even when what is being preserved and renewed does not necessarily 'belong' to the people engaged in those practices. These practices come at least partly, as Sissons has found in urban indigenous contexts in Aotearoa/New Zealand and North America, from academic literature, popular culture such as books, films and even advertisements. ${ }^{6}$ They may be 'borrowed' or 'shared' by other Aboriginal groups in Australia and international Indigenous groups in what is now a global Indigenous exchange. These cultural forms may also come from memories, dreams and imaginings for which there can be no accounting or tracing. But no-one could successfully argue that this is a brand new genesis, a made up identity, or a nostalgic post-modern 'simulacrum'. The identity produced by Alma's mob is the product of political strategising and manoeuvring, as well as extensive social relations. This is a political-cultural process of group identity formation and development.

The group of Galba who compete with Alma's group for the attention of white authorities (henceforth referred to as Group X) have based their claims to authentic Galba identity and ownership on genealogies and on academic research on language, archaeological sites and historical documents. This research is used to make native title and other kinds of claims against the Australian state, a very different form of identity making from Alma's mob who make public spectacles of their cultural practices. Group $\mathrm{X}$ do not claim, and in fact emphatically disparage any claim to ongoing cultural practices such as the dance, art production or language use which are important expressions of identity used by Alma's mob. Group X claims are connected to a modern political identity but one which still must have at its root the 'authenticity' that the Australian state demands for native title claimants: that is, ongoing connection to Aboriginal traditions and customs. This kind of political emphasis on Indigenous identity in a Native American context has been labelled 'political nationalism' by Gerald Sider. ${ }^{7}$ Group X, the Galba political nationalists, claim that such displays of culture as dance, art and language-use damage their own claims to an authentic, modern, political Galba identity, further emphasising a schism between the two Galba groups. ${ }^{8}$

I was also unaware at that time that in being Alma's long term friend I had already been identified by both groups of Galba and their various supporters and detractors as a supporter of Alma's mob rather than as a supporter of Aboriginal people generally as I had perceived myself. Moreover, in conducting the research related to the biography I was affirming the position of 'Alma partisan'. It was not until I had conducted participant-observation fieldwork that I realised the extent of the schism between the groups and the impossibility 
of working with them both due to my history of working with Alma and her community.

This impossible positioning of researchers as supporters of one group or the other results from competition between groups for the attention of whites and is as true for government agents and private stakeholders as it is for researchers (both Indigenous and non-Indigenous). It is a result of a phenomenon that is common in many postcolonial contexts; Jeffrey Sissons calls it 'oppressive authenticity' 9

'Oppressive authenticity' is largely a result of the ways that courts determine Indigenous groups' eligibility for land claims, and in Australia, especially native title, arguably the ultimate recognition of Indigenous 'authenticity'. As Francesca Merlan explains, the incomparability of Aboriginal land rights with other kinds of property rights is legislatively managed in the Aboriginal Land Rights Act (NT 1976). ${ }^{10}$ This is done by elaborate codification of what needs to be demonstrated to succeed as well as the creation of a new form of property title. The Commonwealth Native Title Act 1993, however, leaves what counts as 'custom' or 'tradition' for determination by the court. This is necessary because whereas land rights are a new form of land title in Australian law, native title is part of Australia's common law. From a legal point of view the basis for the existence of native title is the presentation of evidence that native title has always existed over a given place for specific people. Indigenous Australians can only demonstrate their continued relationship with a specific place by demonstrating their association with that place in terms of the court's interpretation of what counts as tradition because it is on the very different traditions to those of other Australians that their distinctiveness is grounded. Indigenous peoples' claims to prior occupation of Australia are based on their difference, and their difference is demonstrated in their traditions. ${ }^{11}$ Because of this, Indigenous subjects of biography are compelled to present their stories in terms of their 'connections' to these traditions.

Courts, as Merlan demonstrates, have recognised sufficient evidence of ongoing Aboriginal tradition for the purposes of native title using highly essentialised notions of the term. That is, courts have used an immutable, static model of 'tradition' and 'custom' to demonstrate that claimants have always had a connection to the place they claim under common law, or one that recognises some change in the nature of cultural objects but constancy in the underlying social processes associated with those objects: guns instead of spears, acrylic paint instead of ochre, and motor bikes instead of walking, for example. ${ }^{12}$ For native title to succeed, authentic Aboriginal tradition needs to consist in static essences and an ontology of fixed and unchanging meanings so as to demonstrate the immutable character of traditional Aboriginal ownership. The trouble with this is that the character of tradition as lived by people in the here and now is 
not consistent with a model of tradition as fixed, immutable and situated in a primordial moment before whites came to Australia. Indigenous Australians are faced with an impossible double bind. On the one hand, the courts require evidence of Aboriginal tradition and custom as unchanged, on the other, forced and voluntary participation in modern Australian life has required drastic and virtually total change from traditional (pre-contact) life ways. Biographers of Indigenous subjects are similarly placed in this double-bind. How can the dynamic circumstances of an Indigenous biography be represented while preserving legal requirements for static tradition?

The courts demand demonstration of fixed and unchanging traditions being performed by specific people in relation to a particular place to allow native title, yet, it is the Australian state (represented by that same court) which is primarily responsible for the kinds of radical cleavages with tradition that are used as evidence of a group's alienation from their traditional lands. I agree with Kalpana Ram when she says that 'authenticity' becomes virtually impossible to obtain in such circumstances, but because ongoing connection to land is a state imposed criterion for demonstrating collective identity, questions of authenticity become impossible to avoid. ${ }^{13}$ Indigenous Australians who want to be recognised as authentic traditional owners must therefore demonstrate evidence of continuing reproduction of traditions associated with the claimed land even if this means that such traditions could only have survived as a result of being subversively performed during eras when traditional Aboriginal cultural practices were prohibited by Australian law. Such traditions must also be demonstrated even if current social conditions make them irrelevant or redundant. 'Connection' to these traditions can often only be substantiated by exhaustive, long term and ongoing research requiring the support of sympathetic white researchers often creating hostile relations with competing groups. State regimes of 'oppressive authenticity' only recognise the claims of a shrinking category of Indigenous peoples who are considered authentic because they can demonstrate ongoing traditional practices in relation to a place, and deny the claims of an ever growing group judged inauthentic because they cannot. ${ }^{14}$ Biographers and their Indigenous subjects are thus placed in the position of both wanting and needing to 'tell the story', but to make that story one that does not undermine illogical and oppressive demands to demonstrate 'ongoing connections' to pre-contact traditions.

This has led, as it has in the Galba case, to many Indigenous groups splitting into factions that have different ideas about how to best demonstrate their authenticity. Group X base their claims to authentic Galba identity and ownership on genealogies and academic research on language, archaeological sites and historical documents. This research is used to make native title and other kinds of claims against the Australian state: another form of identity making. Alma's 
mob, as well as using genealogical evidence based on family history research practice a kind of 'strategic essentialism', which I explain below, to make claims to authentic Aboriginal identity and ownership.

Although courts use a highly essentialised notion of 'tradition' and 'custom' to determine a group's eligibility for native title, Francesca Merlan points out that public and academic understandings of Indigenous tradition do recognise that change in the form of adaptations, discontinuities and reconfigurations are inevitable, especially in colonial regimes which inflict such change. ${ }^{15}$ Clearly, 'we' (academics and the general public) take a different view of the terms 'authenticity' and 'tradition' from that of the courts; biographers of Indigenous stories can play a role in further stretching the boundaries of these clearly flawed categories. But, as I will argue below, 'we' still retain at the core of our understanding, a conceptualisation of tradition as a bridge between past and present or the continuation of the past in the present. ${ }^{16}$ As Ram reminds us, the relatively recent and pervasive postmodern critique of 'truth' still leads us to understand 'tradition' as a kind of 'essentialism', but an essentialism which only allows us to see traditions and the authenticity they claim to represent as political strategies. ${ }^{17}$ These postmodern critiques are rightly based on an argument that any version of 'authenticity' and 'truth' which sees reality as essence, fixed and persistent over time, is illogical. But, 'we' (western thinkers) are not free from this tradition of thought, we must engage with this tradition because we are part of the history of western logic. Ram draws on Derrida to explain that although 'we' (westerners) know that tradition is changing and negotiable, we still need to engage with a metaphysics which sees tradition as immutable because such an understanding is part of 'our' intellectual heritage. ${ }^{18}$

It is not, however, only 'us' who need to engage with this contradiction but also minority groups who are not necessarily heirs to this tradition of thought, but who are dominated by it. Such groups, Indigenous Australians being one of them, need to politically manage such a questionable metaphysics by strategically engaging with it. That is, by recognising terms such as 'authenticity' and 'tradition' as contradictions of lived experience and using those contradictions to their advantage. 'They' (the colonised) need to take 'our' (the colonisers) ideas about 'their' traditions and use those ideas in ways which will benefit them politically and culturally. Indigenous subjects of biography can and do collaboratively strategise with their biographers to do this.

Alma's mob certainly make strategic use of essentialism. They use certain motifs in their paintings which are familiar to 'us' (the dominant culture) in central desert 'dot' paintings to represent their Aboriginality. They draw from various, but recognisably Aboriginal styles of dance in their performances. They ritually use a version of a pre-contact Galba language, which even if it is criticised as inauthentic, sounds like an Aboriginal language as such languages are represented 
in films, radio and how 'we' might imagine a 'primitive' language to sound. These practices are then represented in biographies and other texts as examples of the ways in which Alma's mob are 'connected' to past Aboriginal cultural practices.

But we need to be careful about the way strategic essentialism is theorised. It can, indeed, be understood as a manifestation of 'oppressive authenticity' if people are forced to behave in ways prescribed by a dominant culture in order to be recognised as possessing a particular identity. But it is often not recognised that people who have been previously dispossessed and have only been left with fragments of their culture do not always understand 'essentialised' cultural practices as solely political. In the case of Alma's group and many others I suspect, strategic essentialism is not all that is at the heart of their (re)invented culture. Older, more socially senior community members teach younger people and new-comers how to perform traditional practices 'properly' - they need to be performed by an appropriate person in an appropriate setting and they need to be performed to a standard. It is not enough to merely perform ceremonies, paint, make speeches or dance. These things need to be learnt and done with panache. A successful performance of a Galba tradition produces a relationship between the performance and the knowledge and social conditions from which the performance is drawn. It is not a performance by a detached artist, but a relationship between performers and audience which, in the case of Alma's community, is usually (but not always) between them and white people. These performances are aimed at representing sentiments, different versions of stories, experiences and traditions which are part of the relationship between community members and between them and 'outsiders'. This is, of course, highly political, but it is also very much about expressing and asserting self-respect, dignity and pride. This is something else that biographers can help Indigenous people express and record.

So, in contrast to Group X, who aim to conform to state ideas about how they should represent themselves as authentic with the goal of a successful native title claim, Alma's mob aim for popular recognition of their existence as authentic Aboriginal people with arguably less concern for their success or failure in the courts.

Clearly, Alma's group define themselves differently from the ways in which they are defined by 'us' (the dominant society). This is more than resistance and more than opposition to state rules and regulations, although it is certainly this in part. Alma's mob use 'strategic essentialism' to (re)invent traditional cultural practices and biography can be used to represent these practices in a way that can be taken seriously by 'us' without recourse to the courts. This is regardless of the fact that such behaviour could undermine their own and Group X's native 
title claims. Because they try to do this a schism has been created between Alma's mob and Group X.

As I said earlier, I had little appreciation for these politics when we began to collect material for the writing up of Alma's biography, or even after we had drafted it. It was not until I had begun to analyse the data I had collected for the ethnography that I realised some information Alma had divulged during our interviews for the biography contradicted some claims to genealogical and cultural continuity which is essential for successful native title claims according to the Commonwealth Native Title Act 1993. While writing the biography I had no idea what was at stake for Alma's mob, for myself, and particularly for Group $\mathrm{X}$ in publicly revealing certain information. Later I realised that Alma's mob have become, if not blasé about state definitions of 'authenticity', then at least philosophical about not always conforming to them. A senior member of Alma's mob told me that Galba people have nothing to hide. The problem, according to him, is with native title rules concerning who and what counts as real, not with how people think about themselves.

Group X undoubtedly also think about themselves in their own ways, but their public articulations of authentic Aboriginal identity are inextricable from the process of making native title claims.

Of course I am concerned about not representing the new, dynamic, self-determining identity that my friends assert. I am also embarrassed and worried about breaking a promise and straining relationships, but I am also concerned for the representations of Group X. In native title claims both groups are joined together. My work could, potentially, diminish the claims of both groups.

Where does this leave Alma's and my relationship? What can and will happen to the biography? It has now been seven years since we wrote the first draft and in that time Alma and I have negotiated too many personal crises in our relationship to re-count. But Alma and her community are adamant. Together we must work out a way to publish her story which is also the story of the (re)emergence of traditional Aboriginal cultural practices in the metropolis. But, of course, the colonialisms that have vexed relationships between Aboriginal and white people in Australia are not over. Alma and her community's story of self-determined identity making is suppressed by my reluctance to damage the state determined identity of both them and Group X. 'Oppressive authenticity' makes the representation of state-determined Aboriginal identity dominate self-determined Aboriginal identity.

\section{Conclusion}

So, were those who criticise the colonising agendas of white authors in writing other people's stories right all along? I do not think so. This is less an issue of 
misrepresentation and appropriation than it is a moral and ethical dilemma. It is also a dilemma that applies equally to white authors of black people's stories and to black authors of their own stories.

Is this merely a question of courage, or is it a question of needing creative new writing strategies to resist such oppression? I would rather think it is the latter. For myself, my personal ethics make seeking the publication of Alma's biography impossible in the short term, so at least for now, Alma, her community, our readers, and I must be satisfied with theorising our predicament and presenting it in the abstract terms I offer in this paper.

\section{References}

Hall, Stuart (ed) 1980, Culture, media, language: Working papers in cultural studies, 1972-79, Hutchinson in association with the Centre for Contemporary Cultural Studies, University of Birmingham, London.

hooks, bell 1994, Outlaw culture: Resisting representation, Routledge, New York.

Louis Gates, Henry 1989, The signifying monkey: A theory of African-American literary criticism, Oxford University Press, New York.

Macdonald, Gaynor 2002, 'Ethnography, advocacy and feminism: a volatile mix. A view from a reading of Diane Bell's Ngarrindjen Wurruwarrin', The Australian Journal of Anthropology 13(1): 88-110.

Merlan, Francesca 1995, 'The regimentation of customary practice: from Northern Territory land claims to Mabo', The Australian Journal of Anthropology 6(1-2): 64-82.

2006, 'Beyond tradition', The Asia Pacific Journal of Anthropology 7(1): 85-104.

Moreton-Robinson, Aileen 2000, Talkin' up to the white woman: Indigenous women and feminism, University of Queensland Press, St Lucia.

Mudrooroo 1990, Writing from the fringe, Hyland House, Melbourne.

Nash, Manning 1989, The cauldron of ethnicity in the modern world, University of Chicago Press, Chicago.

Ram, Kalpana 2000, 'Dancing the past into life: the Rasa, Nritta and Rāga of immigrant existence', The Australian Journal of Anthropology 11(3): 261-73.

Rhydwen, Mari 1993, Writing on the backs of blacks, University of Queensland Press, St Lucia.

Roosens, Eugeen 1989, Creating ethnicity: The process of ethnogenesis, Sage, London.

Shils, E 1971, 'Tradition', Comparative Studies in Society and History 13(2): 122-59. 
Sider, Gerald 1976, 'Lumbee Indian cultural nationalism and ethnogenesis', Dialectical Anthropology 1: 161-72.

Sissons, Jeffrey 2005, First peoples: Indigenous cultures and their futures, Reaktion Books, London.

Williams, Raymond 1977, Marxism and literature, Oxford University Press, Oxford.

\section{ENDNOTES}

${ }^{1}$ I use pseudonyms throughout this paper to protect the privacy of individuals and groups.

2 Hall 1980; Louis Gates 1989; Mudrooroo 1990; hooks 1994; and Moreton-Robinson 2000.

3 Rhydwen 1993.

4 Macdonald 2002.

${ }^{5}$ Commonwealth Native Title Act 1993.

${ }^{6}$ Sissons 2005: 7.

7 Sider 1976.

${ }^{8}$ Contrast with Roosens 1989 in a Canadian context.

${ }^{9}$ Sissons 2005.

10 Merlan 1995: 65.

11 Merlan 2006: 86.

12 Merlan 2006: 88.

13 Ram 2000: 257.

14 Sissons 2005: 59.

15 Merlan 2006: 93.

16 See Merlan 2006: 86-88; Nash 1989; Williams 1977; and Shils 1971: 123 for some useful definitions.

17 Ram 2000: 258.

18 Ram 2000: 258. 